\title{
Laboratory investigation of high pressure survival in Shewanella oneidensis MR-1 into the gigapascal pressure
} range

\author{
Rachael Hazael ${ }^{1}$, Fabrizia Foglia ${ }^{1}$, Liya Kardzhaliyska ${ }^{1}$, Isabelle Daniel ${ }^{2}$, Filip Meersman ${ }^{1,3}$ and \\ Paul McMillan ${ }^{1}$ *
}

' Christopher Ingold Laboratories, Department of Chemistry, University College London, London, UK

${ }^{2}$ Laboratoire de Géologie de Lyon, UMR 5276 CNRS, ENS de Lyon and Université Claude Bernard Lyon 1 - Université de Lyon, Lyon, France

${ }^{3}$ Biomolecular and Analytical Mass Spectrometry group, Department of Chemistry, University of Antwerp, Antwerpen, Belgium

\section{Edited by:}

Dawn Cardace, University of Rhode Island, USA

\section{Reviewed by:}

Jens Kallmeyer, Helmholtz Zentrum Potsdam-GFZ, Germany

Lingling Wu, University of

Wisconsin-Madison, USA

Magdalena Rose Osburn, University

of Southern California, USA

*Correspondence:

Rachael Hazael and Paul McMillan, Christopher Ingold Laboratories, Department of Chemistry, University College London, 20 Gordon Street, London, WC1H OAJ, UK

e-mail: rachael.hazael@ucl.ac.uk; p.f.mcmillan@ucl.ac.uk
The survival of Shewanella oneidensis MR-1 at up to $1500 \mathrm{MPa}$ was investigated by laboratory studies involving exposure to high pressure followed by evaluation of survivors as the number $(N)$ of colony forming units (CFU) that could be cultured following recovery to ambient conditions. Exposing the wild type (WT) bacteria to $250 \mathrm{MPa}$ resulted in only a minor $\left(0.7 \log N\right.$ units) drop in survival compared with the initial concentration of $10^{8}$ cells $/ \mathrm{ml}$. Raising the pressure to above $500 \mathrm{MPa}$ caused a large reduction in the number of viable cells observed following recovery to ambient pressure. Additional pressure increase caused a further decrease in survivability, with approximately $10^{2} \mathrm{CFU} / \mathrm{ml}$ recorded following exposure to $1000 \mathrm{MPa}(1 \mathrm{GPa})$ and $1.5 \mathrm{GPa}$. Pressurizing samples from colonies resuscitated from survivors that had been previously exposed to high pressure resulted in substantially greater survivor counts. Experiments were carried out to examine potential interactions between pressure and temperature variables in determining bacterial survival. One generation of survivors previously exposed to $1 \mathrm{GPa}$ was compared with WT samples to investigate survival between 37 and $8^{\circ} \mathrm{C}$. The results did not reveal any coupling between acquired high pressure resistance and temperature effects on growth.

Keywords: high pressure biology, Shewanella oneidensis MR-1, bacterial survival, piston cylinder experiments, pressure adaptation studies, variable temperature bacterial growth

\section{INTRODUCTION}

The identification of organisms surviving in deep subsurface habitats has raised important questions concerning the absolute limits of life forms exposed to extreme stresses, including high pressure (Bartlett, 2002; Oger and Jebbar, 2010; Picard and Daniel, 2014). Since the early work of ZoBell and Johnson (1949) a wide range of laboratory and field studies have shown that the survival, growth, and metabolism of surface dwelling species and piezophile organisms are significantly affected by exposure to high pressure conditions (Bartlett, 2002; Colwell and D'Hondt, 2013). Explorations of deep oceanic and continental subsurface habitats have returned organisms whose habitat is at pressures up to $110 \mathrm{MPa}$ (Edwards et al., 2012; Picard and Daniel, 2014). In most environments the limit for microbial life at depths might not be determined by an upper pressure boundary but by the rise in temperature above approximately $120^{\circ} \mathrm{C}$ due to the geotherm (Oger and Jebbar, 2010; Picard and Daniel, 2014). Living organisms might be encountered at higher pressures in deep, cold environments on Earth such as subduction zones as well as other icy planetary bodies like Enceladus, Titan, or Ganymede, so that it is important to investigate the upper limits to bacterial survival as well as the mechanisms that microorganisms employ to counteract extreme pressurization effects. Such work is also important for sterilization processes employing "Pascalization" (high P) vs.
"Pasteurization" (high T) techniques that are increasingly used to preserve color, flavor, texture, and nutritional value among food-related products (Hite et al., 1914; Van Opstal et al., 2005; Aertsen et al., 2009; Demazeau and Rivalain, 2011; Meersman et al., 2013). Experimental studies have begun to investigate the ultimate pressure limits to bacterial survival, both as a result of initial compression of naturally occurring wild type (WT) microorganisms, and following resuscitation of survivors from initial pressurization experiments, that can reveal either adaptation of parts of the population to extreme compression or the elimination of individuals that were less able to resist extreme pressurization.

In a pioneering study Sharma etal. (2002) suggested that bacteria including E. coli and S. oneidensis MR-1 continued to survive and metabolize at pressures up to $1.4 \mathrm{GPa}$, that greatly exceeded the range previously considered for possible pressure limits to life. However, those results and their interpretation were criticized within the microbiological community who noted that the data might simply represent the continuation of enzymatic activity persisting after cell death (Yayanos, 2002; Picard and Daniel, 2014). Our group recently carried out an investigation of $E$. coli survival into the GPa range, using colony formation and counting techniques for samples recovered following high pressure exposure, along with sequential pressure 
treatment of samples taken from survivor colonies following resuscitation (Vanlint et al., 2011). The results showed no detectable survivors or evidence for colony formation from the WT population following applied pressure stress of $700 \mathrm{MPa}$ or above. However, we did observe significant (1-2\%) survival following pressurization extending up to $2 \mathrm{GPa}$, for colonies derived from survivor populations that were resuscitated following multiple exposures to increasing pressure conditions (Hauben et al., 1997; Vanlint et al., 2011). That result could indicate that some fraction of the initial E. coli population contained a biomolecular mechanism to resist such extreme high pressure conditions, and had the ability to be resuscitated and grow upon returning to ambient pressure. This characteristic might be inherited among successive generations following systematic exposure to successively higher pressures. An alternative interpretation is that development of pressure-resistant characteristics could occur within parts of the population as a function of continued pressurization to higher pressures. Our initial E. coli study also examined the possibility of cross-correlation between high $\mathrm{P}$ - and high T-resistant traits emerging among the populations (Vanlint et al., 2011). However, those results showed no correlation between these traits.

In the present work we have extended our studies to $S$. oneidensis MR-1, to conduct an investigation of the combined effects of pressure survival, resuscitation and growth temperature effects on the colony-forming behavior of WT vs. "pressurized" survivor strains. This model organism was selected as a member of the Shewanella genus that contains both facultative and obligate piezophilic species, e.g., S. violacea, S. profunda, and S. benthica (Venkateswaran et al., 1999). We followed a similar experimental protocol to our previous E. coli study using piston cylinder techniques to expose the microbial samples to pressures extending into the GPa range followed by plate counting of survivors (Vanlint et al., 2011), and assessing their ability to resuscitate and establish colonies.

It is important to investigate possible cross-correlation effects between high pressure and variable temperature survival characteristics. S. oneidensis grows optimally at $30^{\circ} \mathrm{C}$ at ambient pressure (Venkateswaran etal., 1999). Within the Shewanella genus several strains grow and thrive in high pressure environments and at cold temperatures. For example S. benthica grows best at just over $50 \mathrm{MPa}$ and $10^{\circ} \mathrm{C}$ (Kato and Nogi, 2001; Lauro et al., 2013) whereas S. frigidimarina is best adapted for growth at ambient pressure and $15^{\circ} \mathrm{C}$ (Bozal et al., 2002). Kato and Nogi (2001) concluded that two sub-genus branches can be considered: Shewanella group 1: high-pressure cold-adapted species, and Shewanella group 2: characterized as mesophilic pressure-sensitive species. S. oneidensis would be classed within group 2 as would S. frigidimarina, whereas $S$. benthica would be classified within group 1 .

In a first set of studies we carried out all pressurization experiments using the WT strain to establish the intrinsic resistance of a population found under ambient conditions and exposed to extreme high $\mathrm{P}$ environments. We then conducted further experiments using survivor colonies established following previous pressurization and resuscitation stages to observe their survival to even higher pressures. Finally, we examined the survival and colony-forming characteristics of WT and P-adapted populations at temperatures extending between 8 and $37^{\circ} \mathrm{C}$.

\section{MATERIALS AND METHODS}

Shewanella oneidensis MR-1 (CIP 106686) was purchased from the Collection Institut Pasteur (Paris, France) (Venkateswaran et al., 1999). These were subsequently rehydrated in $200 \mu \mathrm{l}$ of LuriaBertani Miller (LB) medium. From this $50 \mu \mathrm{l}$ was used for a liquid culture in $10 \mathrm{ml}$ of LB broth to be grown at $30^{\circ} \mathrm{C}$ and $180 \mathrm{rpm}$, and two separate plate spreads of $50 \mu \mathrm{l}$ each allowed stock solutions to be made.

For each experiment a $10 \mathrm{ml}$ starter culture was inoculated either from a plate or from stock. The bacteria were harvested in stationary phase at a concentration of $4 \pm 1 \times 10^{8}$ cells $/ \mathrm{ml}$. For each experiment $1 \mathrm{ml}$ aliquot of the starter culture was washed three times with phosphate buffered saline (PBS) solution adjusted to $\mathrm{pH}$ 7.2. This allows only live bacteria to be present in the sample, as any components of broken cells are washed out and no cell clumps are present. The high pressure capsule was loaded with $700 \mu \mathrm{l}$ of the bacterial suspension. An aliquot of this sample was plated to serve as a control for the pressurized bacterial sample. All microbiological preparations and sample handling were carried out under aseptic conditions.

Pressurization experiments on the microbial suspensions were carried out using a piston cylinder device typically used for experiments in Earth and solid state sciences (Figure 1). This enables high pressure studies to be carried out to $>3 \mathrm{GPa}$ with sample volumes extending up to approximately $700 \mu \mathrm{l}$. This provided sufficient material to ascertain bacterial survival via plate counting techniques on recovered samples, as well as providing samples for further imaging, spectroscopic, and culturing experiments. The bacterial suspensions were loaded into Teflon ${ }^{\circledR}$ capsules (Hill et al., 2011; Vanlint et al., 2011) and placed inside a sleeve preformed from powdered $\mathrm{NaCl}$ that acted as a pressure-transmitting medium. The sample assembly was mounted inside the bore of the pressure plate and the piston introduced from the top. Pressure was then increased by hand pumping a hydraulic ram that allowed the target pressures to be obtained within a few seconds. This is negligible in comparison with the timescale of the pressurization experiments that were typically held at target pressure for $15 \mathrm{~min}$. During the mechanical compression the salt sleeve undergoes plastic flow and provides an approximately hydrostatic pressure transmitting environment surrounding the sample chamber. For variable temperature studies a water bath was constructed using various ice/water mixtures to control the inlet temperature of the cooling coils that surrounded the piston cylinder pressure plate. The sample temperature was monitored by a K-type thermocouple inserted into the base of the sample holder. After calibration the apparatus achieved temperature stability within $\pm 1^{\circ} \mathrm{C}$ over a 30-60 min period spanning the duration of each experimental run. Once the desired $\mathrm{P}, \mathrm{T}$ conditions were reached the sample was held for $15 \mathrm{~min}$ before recovery to ambient conditions, removal from the capsule and subsequently plating and/or otherwise characterizing the bacterial culture obtained. Holding times in the 10-15 min range are typically used in high-pressure food microbiology studies as a convenient compromise between various experimental and biological parameters. 


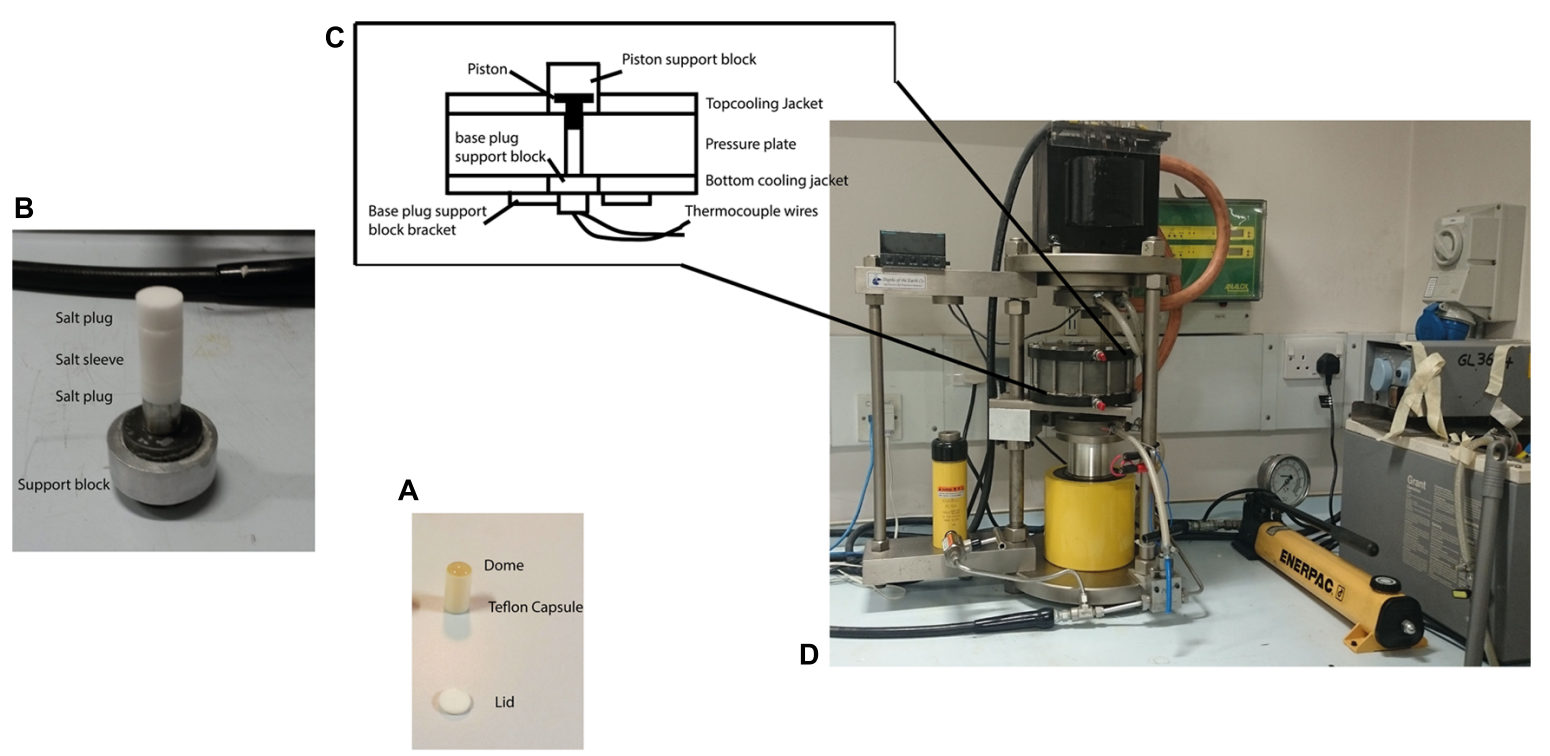

FIGURE 1 |The piston cylinder device (http://www.depthsoftheearth. com) and protocol used for carrying out the high pressure

experiments. (A) The Teflon ${ }^{\circledR}$ capsule is filled with cell suspension and is capped by a Teflon ${ }^{\circledR}$ lid for the experiment. The dome of liquid indicates the capsule is completely filled and contains no air. (B) The capsule is placed inside a pre-formed cylinder (sleeve) made from pressed powdered $\mathrm{NaCl}$ that acts as a pressure-transmitting medium with $\mathrm{NaCl}$ plugs capping both ends. (C) The sample assembly is then placed inside the central bore of the pressure plate. The tungsten carbide piston is inserted from the top. Thermocouple wires inserted from the bottom and passing through the lower pressure support block to make contact with the sample capsule were used to measure the temperature. (D) Pressure is applied by hand pumping the oil-driven hydraulic ram to raise the pressure plate containing the sample assembly and force it against the piston that is driven down to reduce the sample volume. The pressure is transmitted to the sample through slight deformation of the walls of the Teflon ${ }^{\circledR}$ container that maintains its shape and remains intact during the experiment and subsequent recovery.
In previous work on $E$. coli we found that different pressureresistant mutants exhibited differences in inactivation kinetics such that the $\log (N)$ survival counts became indistinguishable for pressurization runs of $45 \mathrm{~min}$ or more (Vanlint et al., 2011). Selecting $15 \mathrm{~min}$ as a run duration allowed a clear distinction between pressure survival characteristics while being substantially long compared with pressure run-up and equilibration times (on the order of $<1 \mathrm{~min}$ ), and remaining within feasible bounds for conducting multiple pressurization-recovery experiments. Kish et al. (2012) found that the E. coli MG1655 strain showed a substantial decrease in survival rate $\left(N / N_{\mathrm{o}}\right)$ in pressure survival experiments at $400 \mathrm{MPa}$ carried out for $60 \mathrm{~min}$, whereas Halobacterium salinarum NRC-1 showed no change in survival at the same pressure, over the same range of experimental run durations. Establishing the relationships between inactivation kinetics and bacterial survival rates as a function of pressure and temperature variables, for different WT vs. pressure-adapted microbial strains, is an important topic to be examined in future work.

The WT bacteria were exposed to pressures extending up to $1.5 \mathrm{GPa}(1500 \mathrm{MPa})$ at $21^{\circ} \mathrm{C}$. Upon decompression to ambient conditions the suspensions were recovered from the capsule and plated onto LB Miller agar following sixfold dilution. Once colonies had developed the number of cells per $\mathrm{ml}(N)$ were determined using plate counting. Most experiments were conducted at least in triplicate (Table 1).
Table 1 | Results of Shewanella oneidensis survival experiments as a function of applied pressure stress at constant temperature $\left(21^{\circ} \mathrm{C}\right)$.

\begin{tabular}{llll}
\hline $\begin{array}{l}\text { Previous pressure(s) } \\
\text { experienced/MPa }\end{array}$ & $\begin{array}{l}\text { Pressure/ } \\
\text { MPa }\end{array}$ & $\begin{array}{l}\text { Survivor } \\
\text { counts/CFU/mI }\end{array}$ & $\begin{array}{l}\text { Average } \\
\mathbf{N} / \mathbf{C F U} / \mathbf{m l} \text { (SD) }\end{array}$ \\
\hline $\begin{array}{l}\text { None (WT) } \\
\text { None (WT) }\end{array}$ & 250 & $9,10,9\left(\times 10^{7}\right)$ & $9.3 \times 10^{7}(60)$ \\
& 500 & $\begin{array}{l}150,140,155 \\
\left(\times 10^{2}\right)\end{array}$ & $1.5 \times 10^{4}(8)$ \\
None (WT) & 750 & $132,130,155$ & $1.4 \times 10^{4}(14)$ \\
None (WT) & & $\left(\times 10^{2}\right)$ & \\
None (WT) & 1000 & $140,927^{\mathrm{a}}$ & $5.2 \times 10^{2}$ \\
250 & 1500 & $132,132,130^{\mathrm{a}}$ & $1.31 \times 10^{2}(1)$ \\
250 and 500 & 500 & $25,24,24\left(\times 10^{5}\right)$ & $2.4 \times 10^{6}(6)$ \\
250 and 500 and 750 & 1000 & $22\left(\times 10^{5}\right)$ & $2.2 \times 10^{6}$ \\
250 and 500 and 750 & 1500 & $5,6,3\left(\times 10^{5}\right)$ & $4.6 \times 10^{5}(153)$ \\
\hline
\end{tabular}

Starting average concentration for WT experiments was $10^{8} \pm 0.5 \mathrm{cells} / \mathrm{ml}$. The decadal exponent in brackets in the survivor counts column refers to the number of successive dilutions carried out. The value in parentheses following the mean average survivor count indicates 1 SD for the nine data points obtained for each sample. For two samples exposed to $1000 \mathrm{MPa}$ insufficient count data were obtained to carry out a statistical test. Each experiment was held at pressure for a duration of $15 \mathrm{~min}$. ${ }^{\text {a }}$ These $\mathrm{CFU} / \mathrm{m} /$ values were determined via plate spreads followed by microscopic examination with no dilution factor. 
To study effects of previous pressure exposure on survival the bacteria were first exposed to an initial pressure value followed by decompression to ambient where the survivors were re-cultured to obtain colonies. One colony picked randomly from the plated survivors was then used to inoculate a starter culture that was taken to a next highest pressure, e.g., $500 \mathrm{MPa}$. That process was repeated sequentially with subsequent survivor cultures exposed to progressively higher pressures, $750 \mathrm{MPa}$ and then $1000 \mathrm{MPa}$. In our highest pressure experiment, samples obtained from the $750 \mathrm{MPa}$ survivor culture were taken directly to $1500 \mathrm{MPa}$.

Variable temperature experiments were conducted using the protocol depicted in Figure 2. In a first series of studies (route A) a $10 \mathrm{ml}$ starter culture of wild type $S$. oneidensis initially grown to stationary phase at $30^{\circ} \mathrm{C}$ and $180 \mathrm{rpm}$ was plated onto LB Miller agar and placed in ovens held at $30^{\circ} \mathrm{C}$ as well as the next lower temperature in the adaptation study, e.g., $25^{\circ} \mathrm{C}$ to observe colony formation at these temperatures (Figure 2). To compare the growth at different temperatures with survivors from extreme pressurization a $10 \mathrm{ml}$ starter culture was then obtained from isolates from an experiment in which the WT strain was taken directly to $1000 \mathrm{MPa}$ (Table 1). The isolates were plated and incubated in separate ovens at 30 and $25^{\circ} \mathrm{C}$ (route $\mathrm{B}$ ). In a third series of experiments (route $\mathrm{C}$ ) the isolates from the $1000 \mathrm{MPa}$ survivors were grown in a $10 \mathrm{ml}$ starter culture, returned to $1000 \mathrm{MPa}$ pressure and held for $15 \mathrm{~min}$. While under pressure the samples were simultaneously cooled to a lower temperature value, beginning with $25^{\circ} \mathrm{C}$. Following recovery, the samples were plated onto LB Miller agar and incubated at either 30 or $25^{\circ} \mathrm{C}$ as before. In a final set of runs,

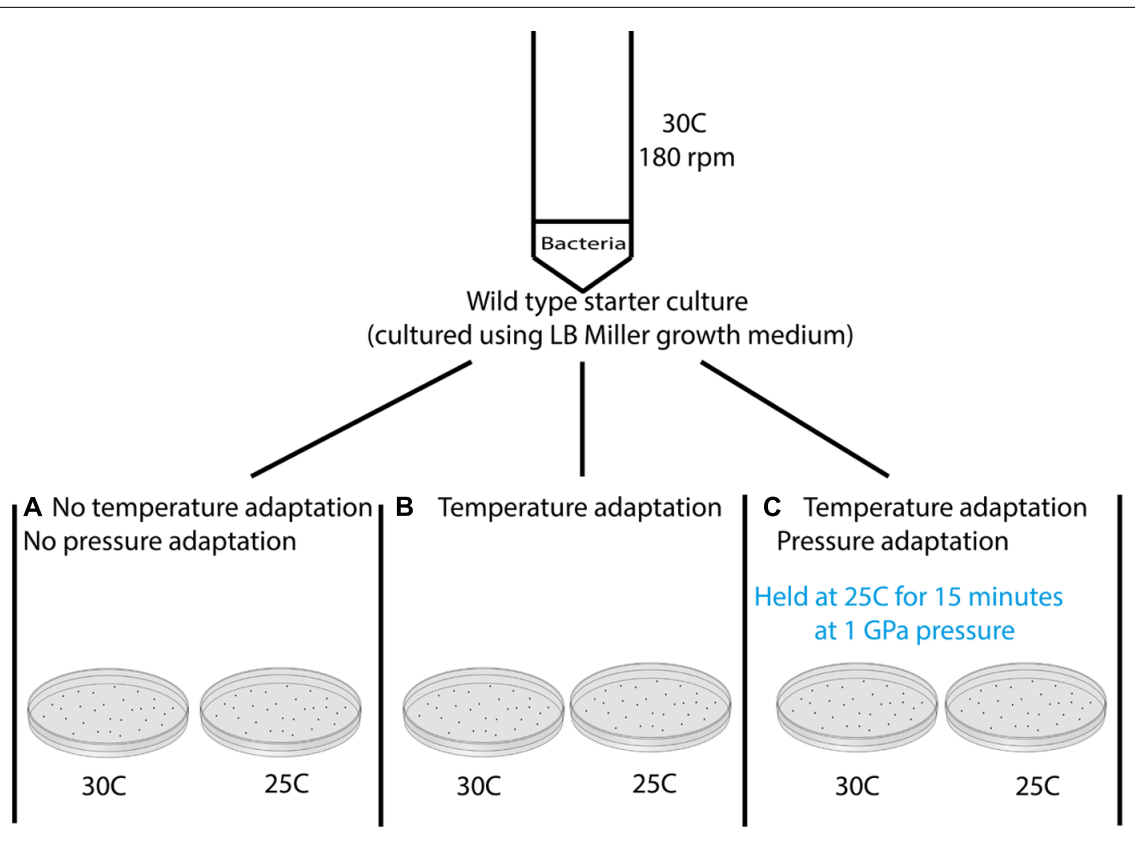

CFUs (Colony Forming Units) counted on the LB Miller agar plates and a randomly picked colony cultured<smiles>C=[14CH]</smiles>

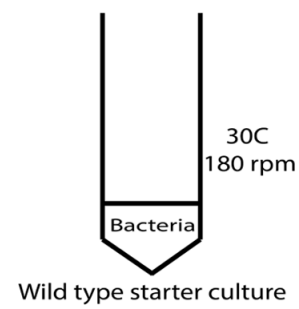

FIGURE 2 | Schematic showing the different steps examined in the variable temperature growth and exposure experiments. Three different treatment protocols are indicated in the figure. Route (A) provides a control experiment for samples exposed to routes (B,C). In route (A) cultures that had previous experienced only ambient pressure and temperature conditions were grown at $30^{\circ} \mathrm{C}$ while being rotated at $180 \mathrm{rpm}$. Once a pellet was obtained the sample was plated and aliquots were incubated at the different temperatures investigated (i.e., 37, 30, 25, 19 , and $8^{\circ} \mathrm{C}$. Colonies formed were counted and the results are shown

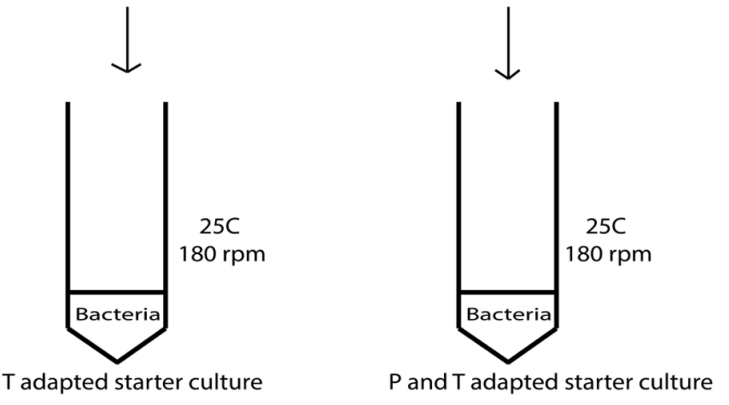

in Table 2. Route (B) cultures were obtained from survivors of the wild type (WT) strain that had been exposed to $1000 \mathrm{MPa}$ (Table 1). These were cultured at $30^{\circ} \mathrm{C}$ and $180 \mathrm{rpm}$ from stocks created from the survivor population. Each sample was then incubated at different temperatures $\left(37,30,25,19\right.$, and $\left.8^{\circ} \mathrm{C}\right)$. Route (C) cultures were likewise isolated from survivors of the initial $1000 \mathrm{MPa}$ exposure experiment, cultured at $30^{\circ} \mathrm{C}$ and $180 \mathrm{rpm}$ from stocks. In the next step these samples were exposed to different temperatures $\left(30,25,19\right.$, or $\left.8^{\circ} \mathrm{C}\right)$ while being held once more at high pressure (1000 MPa). 
we attempted a directed temperature study similar in protocol for the pressurization experiments. From the LB Miller agar plate incubated from the $1 \mathrm{GPa}$ pressure survivors at $25^{\circ} \mathrm{C}$, a colony was isolated, cultured, prepared as above and then re-exposed where it was held for $15 \mathrm{~min}$ at a lower temperature (e.g., $19^{\circ} \mathrm{C}$ this was then repeated and the temperature decreased further to $\left.8^{\circ} \mathrm{C}\right)$.

\section{RESULTS SURVIVABILITY FOLLOWING PRESSURIZATION AT ROOM TEMPERATURE}

In a first series of experiments, wild type $S$. oneidensis MR-1 bacteria were taken directly to pressures of 250, 500, 750, 1000, and $1500 \mathrm{MPa}$ and recovered to ambient conditions. The number of survivors following each pressurization experiment was determined as the number of colony forming units (CFU) per $\mathrm{ml}(\mathrm{N}$; Table 1; Figure 3). The numbers of surviving CFU/ml dropped rapidly above $250 \mathrm{MPa}$ with a decrease of 4-5 log $(N)$ units by $500 \mathrm{MPa}$. By $1000 \mathrm{MPa}$ only 130-140 cells/ml could be detected in the recovered sample; however, those highly P-resistant individuals could be successfully cultured and they were used for the pressuretemperature cross-correlation studies described in the next section (Table 1). Although no statistical analysis is possible from the limited data set the variation in $N$ values between individual runs gives an indication of the reproducibility, and the spread in values is used to estimate the error bars shown in Figure 3.

At the highest pressure achieved in this study (1500 MPa) our results demonstrated that a few cells were able to survive this extreme pressurization treatment and form colonies following recovery to ambient. These survivors (WT) showed a $6 \log$ unit reduction from the original starting concentration, but only a 3.5 log unit reduction in comparison with resuscitated "P-adapted" survivor colonies that had also been taken to $1500 \mathrm{MPa}$ (Table 1; Figure 3).

In a next series of pressure survival experiments we added resuscitation steps to investigate the possibility of "directed evolution" following initial exposure to high pressure conditions (Vanlint et al., 2011). The results shown in Figure 3 compare data for the wild type strain taken directly to each pressure with experimental runs in which survivors from an initial pressure exposure (e.g., $250 \mathrm{MPa}$ ) were plated and re-cultured. From Figure 3 it is evident that the bacteria cultured following the pressurizationresuscitation protocol had a significantly higher degree of pressure survival than the WT strain, with the pressurized-resuscitated strain reaching a survival count of four orders of magnitude higher at 1000-1500 MPa. Both data sets appear to show the largest reduction in survival between 250 and $500 \mathrm{MPa}$. Above that pressure the WT strain continued to be reduced in its number of survivors, but the pressure-adapted strain appeared to increase by approximately $1 \log (N)$ unit for the 750 and $1000 \mathrm{MPa}$ pressure points. After $1000 \mathrm{MPa}$ the survival counts showed a reduction to below the $500 \mathrm{MPa}$ survival at $1500 \mathrm{MPa}$ (Figure 3).

\section{COMBINED EFFECTS OF EXPOSURE TO VARIABLE PRESSURES AND TEMPERATURES}

The results of our experiments carried out to investigate potential pressure-temperature cross-correlation effects are detailed in

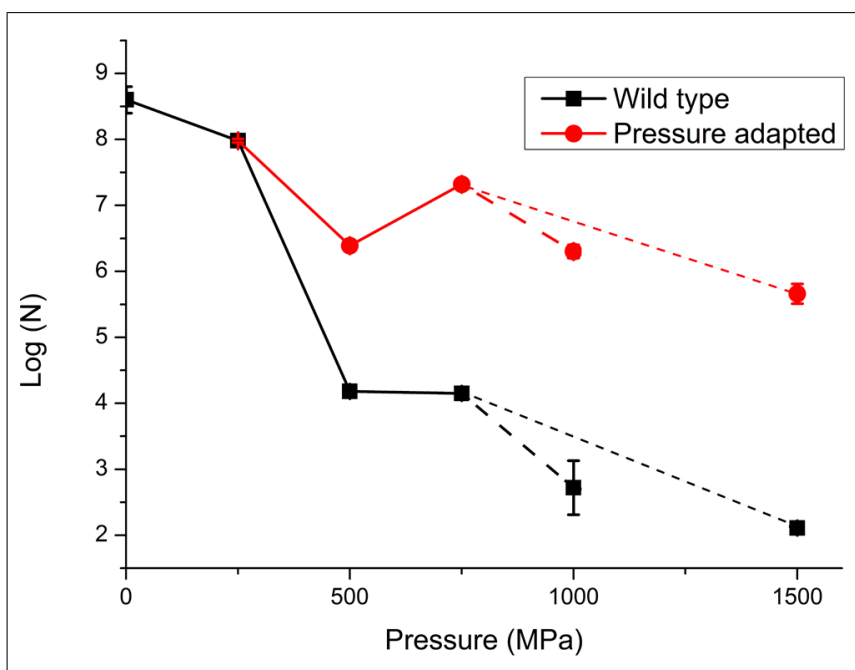

FIGURE 3 | Survivability of $S$. oneidensis MR-1 following exposure to high pressure extending up to $1000 \mathrm{MPa}(1 \mathrm{GPa})$. Data are reported on a logarithmic scale with $N$ as the number of CFUs per ml determined following recovery to ambient pressure. Data points represent averaged results from multiple experiments: individual run results are listed in Table 1. The point at $0.1 \mathrm{MPa}$ (ambient pressure) represents the starting solution with initial concentration $10^{8} \pm 0.5 \mathrm{cell} / \mathrm{sl}$. The lines are sketched to show a link between data points. In a first series of experiments the WT strain was taken directly to each pressure of $250,500,750$, and $1000 \mathrm{MPa}$ in single steps. In further experiments the survivors following pressure exposure were cultured to form a "pressure adapted" population, that was then exposed to a next higher pressure step. The sequential process of pressure exposure, survivor culture, then subsequent exposure to higher pressure was repeated several times for different samples. Dashed lines extending to $1 \mathrm{GPa}$ (larger dashed lines) and 1.5 GPa (smaller dashed lines) points represent different pathways for pressure exposure, survivor culture that were taken after $750 \mathrm{MPa}$, (pathway 1:250, 500, 750, and $1000 \mathrm{MPa}$ and pathway 2: $250,500,750$, and $1500 \mathrm{MPa}$ ). Details of individual experiments are given in Table 1. Size of the data marker and error bars indicate the range of CFUs counted for each data point.

Table 2 (Supplementary Information). As for the pressurization experiments an initial culture of the starter WT pellet with concentration $10^{8} \pm 0.5$ cells $/ \mathrm{ml}$ was grown at various temperatures (Figure 2). We observed relatively little variation between 37 and $19^{\circ} \mathrm{C}$ but the number of viable $\mathrm{CFU} / \mathrm{ml}$ observed following exposure to $8^{\circ} \mathrm{C}$ dropped by approximately 4 log units (Figure 4). We found no obvious pressure-temperature crosscorrelation effect within the same temperature range for the strain that had been previously exposed to $1000 \mathrm{MPa}$ and cultured at $30^{\circ} \mathrm{C}$, although that strain appeared to show lower survival at $8^{\circ} \mathrm{C}$ than the WT strain. In further experiments (see Figure 2 for a detailed description of the protocols followed) we observed that the high pressure $(1000 \mathrm{MPa})$ survivors cultured at a lower temperature $\left(25^{\circ} \mathrm{C}\right)$ and plated at $30-19^{\circ} \mathrm{C}$ did show a small increase in viability (Figure 4). Showing that the change in culturing temperature from 30 to $25^{\circ} \mathrm{C}$ had a small affect on the viability of the cells. Finally, we attempted several experiments in which the cultivated $1 \mathrm{GPa}$ survivors were simultaneously exposed to a further $1 \mathrm{GPa}$ treatment at various temperatures, but no obvious trend in $\log (N)$ values could be distinguished (data listed in Table 2, but not included in Figure 4 for clarity). 


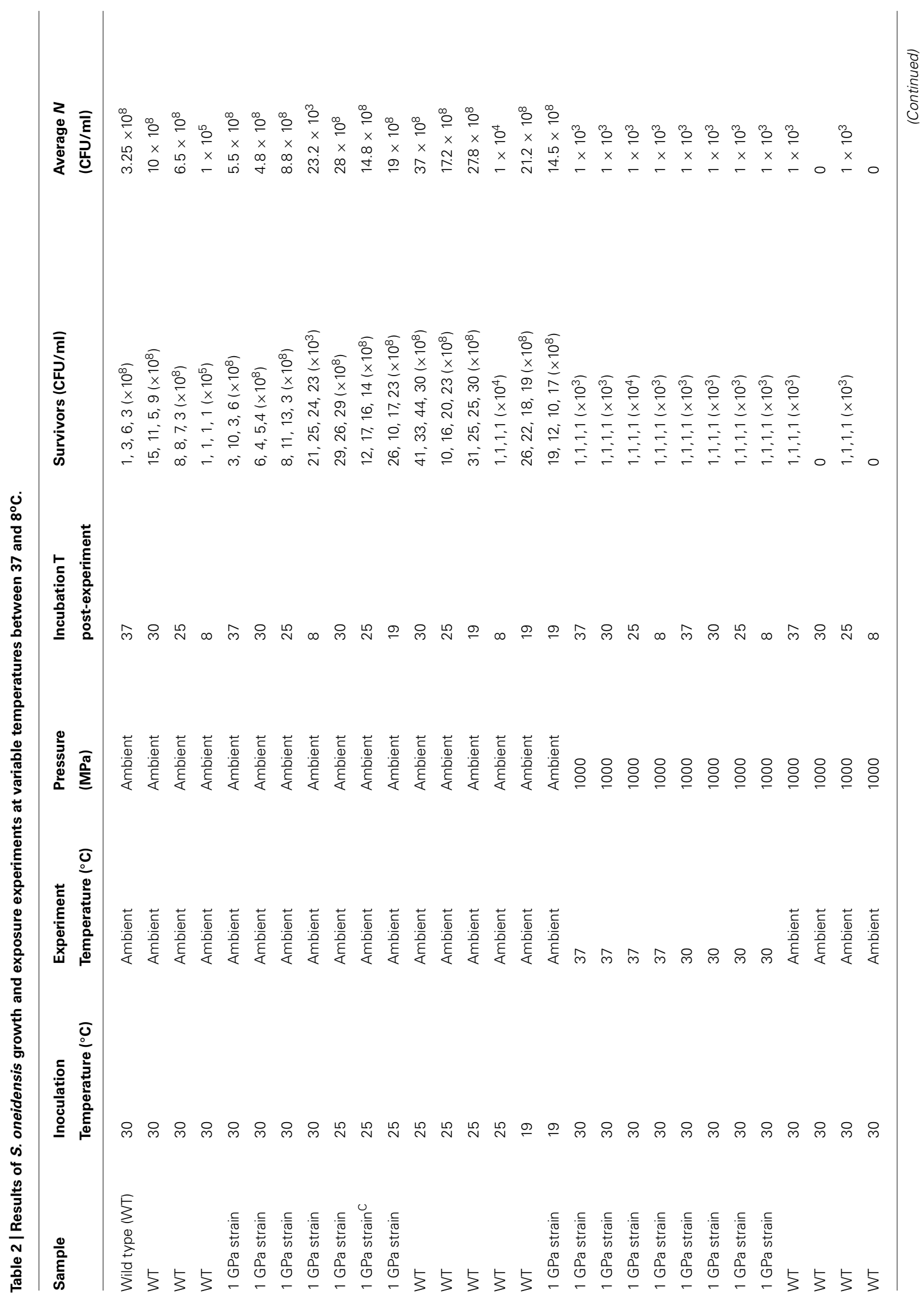




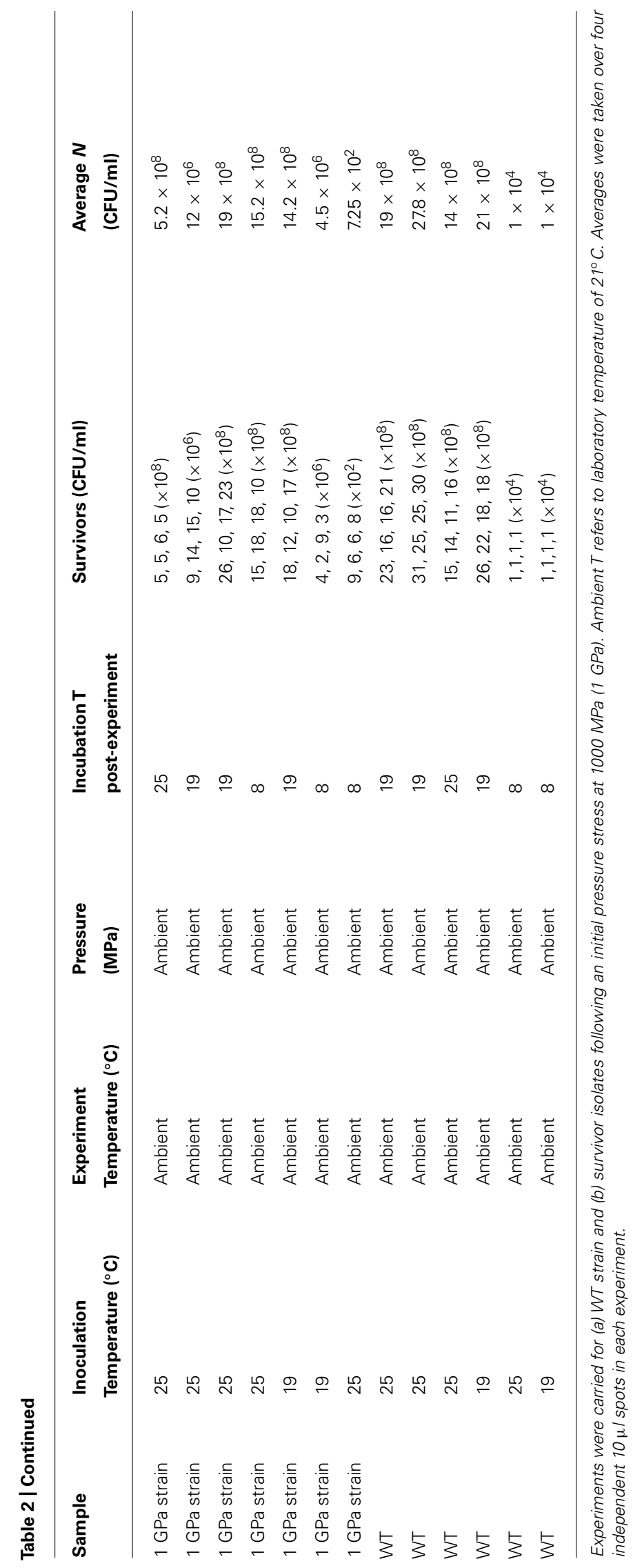




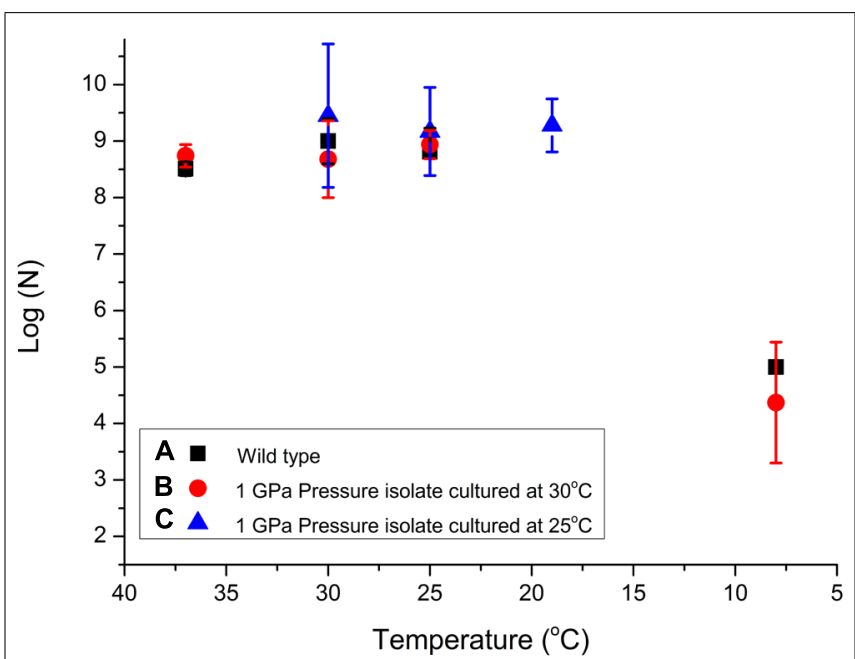

FIGURE 4 | Examination of $S$. oneidensis survival following exposure to different sets of temperature and pressure conditions to investigate possible cross-correlation effects. Table 2 shows the raw data $(N)$ for the T experiments. Data points showing log (N) are compared for (A) WT bacteria previously cultivated at $30^{\circ} \mathrm{C}$ then exposed for $15 \mathrm{~min}$ at temperatures between 37 and $8^{\circ} \mathrm{C}$ (black squares); (B) samples from a colony resuscitated following exposure to $1 \mathrm{GPa}$ pressure, subsequently cultured at $30^{\circ} \mathrm{C}$, and then exposed to temperatures between 37 and $8{ }^{\circ} \mathrm{C}$ (red circles); (C) resuscitated samples previously exposed to $1 \mathrm{GPa}$, cultured at $25^{\circ} \mathrm{C}$, then re-exposed to temperatures between 37 and $8^{\circ} \mathrm{C}$ (blue triangles). Individual run data results are reported in Table 2. Size of the data marker and error bars indicate the range of CFUs counted for each data point.

\section{DISCUSSION}

Our experiments show two main results. First, WT samples of $S$. oneidensis MR-1 exhibit a rapid decrease in survival above $250 \mathrm{MPa}$, with a decrease of $4.5 \mathrm{log}$ units in $\mathrm{CFU} / \mathrm{ml}$ that can be cultivated following exposure to $500 \mathrm{MPa}$. The survivor counts continue to decrease further upon exposure to higher pressures, but viable CFUs were still present at $1500 \mathrm{MPa}(1.5 \mathrm{GPa})$. The observation that even a small proportion of individuals can survive such extreme pressurization conditions is remarkable, that has only been suggested previously by the pioneering study of Sharma et al. (2002). These authors showed spectroscopic evidence for respiration by in situ diamond anvil cell studies of a similar strain exposed to pressures up to $1680 \mathrm{MPa}$. However, they also found that E. coli in its wild type state showed similar metabolic activity over the same pressure range, whereas our recent pressurizationcultivation experiments found no detectable CFUs among samples exposed to above $750 \mathrm{MPa}$ (Vanlint et al., 2011). The rate of pressure drop in survivability between 250 and $500 \mathrm{MPa}$ found for WT E. coli was much lower, however, decreasing by only $2.5 \mathrm{log}$ $(N)$ units over this range. It is obvious that the rate of decrease in bacterial survivability with exposure to extreme pressure stresses is highly species dependent. Wuytack et al. (2002) tested the survivability of 11 bacterial strains at pressures up to $400 \mathrm{MPa}$. They found that all microbes showed a similar large increase in cell death above $250 \mathrm{MPa}$, and they noted that Gram-negative bacteria (including Shewanella) appeared to show a lowered aptitude for high pressure survival than the Gram-positive examples included in their sample. These results raise interesting questions concerning the role of cellular structure in determining the degree of survival into extreme pressure ranges, among populations that have become adapted to live and grow under particular sets of environmental conditions.

Our second principal result concerns the high degree of survivability developed among randomly selected parts of surviving populations that had been resuscitated following initial exposure to high pressure treatments. In extensive studies of E. coli exposed to pressures up to $700 \mathrm{MPa}$, food technology researchers have identified genetic factors that may contribute to extreme pressure resistance (Hauben et al., 1997; Aertsen et al., 2004; Vanlint et al., 2013a,b). These authors reported an up regulation in RpoS activity compared with the parent strain, that could imply that genetic mutations play an important factor in developing pressure resistance (Griffin et al., 2011; Vanlint et al., 2013a,b; Meersman and McMillan, 2014). An independent study on L. monocytogenes shows an ability to mutate various protein sequences can allow the presence of a certain number of cells that are resistant to stress, even within the wild type population. This would then enable a subpopulation to survive under various stress conditions (Karatzas et al., 2005). However, in our present study of S. oneidensis it is known that only 1-2 doubling events should be expected during the 15 min experimental run time (Abboud et al., 2005), assuming that ambient pressure doubling rates apply. It is documented that bacterial metabolism slows considerably as a function of pressure implying that a reduction in growth rate would be expected (Picard etal., 2012). It thus seems unlikely that genetic modifications within individual cells would give rise to the observed pressure resistance acquired by selected elements of the population in our laboratory studies.

Studies have suggested that various biochemical effects can be implicated in extremophile survival strategies including changes in intracellular salt content and cell wall biochemistry (Bartlett, 2002; Griffin etal., 2011; Kish etal., 2012; Meersman etal., 2013), as well as other factors that have been identified as important in defining cellular integrity at high pressure (Allen et al., 1999; Allen and Bartlett, 2000; Schuster and Sleytr, 2002; Kawamoto et al., 2011; Picard and Daniel, 2014). It has been noted recently that lipid bilayer structures are templated on peptidoglycan layers such as those that form the outer cell wall of Gram-negative bacteria that could suggest a link to proteomics effects among the pressure-resistant parts of the population (Subramaniam et al., 2013).

We did not observe any clear cross-correlation between T- and P-response effects affecting survival in S. oneidensis. That result mirrors our previous report for E. coli, where no obvious correlation between high pressure and high temperature adaptability could be detected (Vanlint et al., 2011). Hauben et al. (1997) similarly concluded that there is no evidence for a correlation between pressure and temperature resistance, or indeed any common inactivation mechanism.

However, some studies have indicated evidence that such a P,T bacterial survival correlation does exist (Iwahashi et al., 1993; Benito etal., 1999; Balny etal., 2002), that is critically important for the food industry (Cheftel, 1995). Aertsen et al. (2004) showed $100 \times$ higher survival for bacteria that were exposed to 
heat shock prior to pressure exposure than those cells that were not heat shocked first. They suggested that an increase in the heat shock protein (HSP) DnaK expression is key to the bacterial cell survival under the combined stress conditions. For $S$. oneidensis, Yin and Gao (2011) proposed that the appearance of HSP and other stress-related proteins share some common features (Guo et al., 2004, 2006). In both cases $\sim 15 \%$ of the total genes experience a significant change over a $25 \mathrm{~min}$ period, that is similar to the 15 min timescales over which our P,T-exposure experiments were conducted. However, other studies have found no obvious correlations between HSPs and the emergence of pressure-resistance (Hartl, 1996; Feder and Hofmann, 1999; Hartl et al., 2011).

Further studies using libraries constituted from experimentally controlled pressure-adapted strains such are those produced here will be essential for developing our understanding of bacterial survival mechanisms in such extreme stress environments.

\section{CONCLUSION}

Our data clearly show that fractions of an initial wild type $S$. oneidensis population survive following exposures to pressures extending into the gigapascal range. As found previously for E. coli (Vanlint etal., 2011), the survival improves if progressive increasing pressure stresses are applied to populations that have been resuscitated and cultivated from survivors of previous exposure to high pressure conditions. It is not clear if the "directed evolution" process involves a genetic, proteomic, or other biochemical response among the general population or simple selection of a small proportion of pre-conditioned survivors. However, the recovered samples have the ability to form colonies following recovery to ambient conditions. Our results indicate the survival for both WT and pressure adapted populations decreases rapidly following exposure to pressures in the 250-500 $\mathrm{MPa}$ range. The decrease in colony forming activity among the survivors appears to occur more rapidly for S. oneidensis than previously found for $E$. coli. There does not appear to be any obvious cross-correlation between the acquisition of pressure- and temperature resistance among the populations, except perhaps at the lowest temperatures where growth kinetics are minimized. S. oneidensis populations previously exposed to $1 \mathrm{GPa}$ pressure exhibit substantially lower numbers of CFUs/ml following standard counting protocol conditions. These results fully demonstrate that bacterial survival following exposure to pressures into the GPa range can occur, but the survival mechanisms are not well established. Pursuing future studies of the bacterial genome, proteomics and cellular biochemistry and mechanisms both in situ and from pressure isolates from such laboratory studies will provide essential information for understanding the existence and function of organisms that survive under extreme high pressure and other applied environmental conditions.

\section{ACKNOWLEDGMENTS}

This study was supported by the Leverhulme Trust and the Deep Life program of the Deep Carbon Observatory (Sloan Foundation). We thank Mr. Moneeb Mirza for assistance with the high pressure and variable temperature experiments.

\section{REFERENCES}

Abboud, R., Popa, R., Souza-Eglpsy, V., Glometti, C. S., Tollaksen, S., Mosher, J. J., et al. (2005). Low temperature growth of Shewanella oneidensis MR-1. Appl. Environ. Microbiol. 71, 811-816. doi: 10.1128/AEM.71.2.811-816.2005

Aertsen, A., Meersman, F., Hendrickx, M. E. G., Vogel, R. F., and Michiels, C. W. (2009). Biotechnology under high pressure: applications and implications. Trends Biotechnol. 27, 434-441. doi: 10.1016/j.tibtech.2009.04.001

Aertsen, A., Vanoirbeek, K., De Spiegeleer, P., Sermon, J., Hauben, K., Farewell, A., et al. (2004). Heat shock protein mediated resistance to high hydrostatic pressure in Escherichia coli. Appl. Environ. Microbiol. 70, 2660-2666. doi: 10.1128/AEM.70.5.2660-2666.2004

Allen, E. E., and Bartlett, D. H. (2000). FabF is required for piezoregulation of cis-vaccenic acid levels and piezophilic growth of the deep-sea bacterium Photobacterium profundum strain SS9. J. Bacteriol. 182, 1264-1271. doi: 10.1128/JB.182.5.1264-1271.2000

Allen, E. E., Facciotti, D., and Bartlett, D. H. (1999). Monounsaturated but not polyunsaturated fatty acids are required for growth at high pressure and low temperature in the deep-sea bacterium Photobacterium profundum strain SS9. Appl. Environ. Microbiol. 65, 1710-1720.

Balny, C., Masson, P., and Heremans, K. (2002). High pressure effects on biological macromolecules: from structural changes to alteration of cellular processes. Biochim. Biophys. Acta. 1595, 3-10. doi: 10.1016/S0167-4838(01) 00331-4

Bartlett, D. H. (2002). Pressure effects on in vivo microbial processes. Biochim. Biophys. Acta. 1595, 367-381. doi: 10.1016/S0167-4838(01) 00357-0

Benito, A., Ventoura, G., Casadei, M., Robinson, T., and Mackey, B. (1999). Variation in resistance of natural isolates of Escherichia coli 0157 to high hydrostatic pressure, mild heat and other stresses. Appl. Environ. Microbiol. 65, 1564-1569. doi: 10.1128/AEM.67.10.4901-4907.2001

Bozal, N., Montes, M. J., Tudela, E., Jimenez, F., and Guinea, J. (2002). Shewanella frigidimarina and Shewanella livingstonensis $\mathrm{sp}$. nov isolated from Antarctic coastal areas. ISEM 52, 195-205.

Cheftel, J. C. (1995). High pressure, microbial inactivation and food preservation. Food Sci. Tech. Int. 1, 75-92. doi: 10.1177/108201329500100203

Colwell, F. S., and D'Hondt, S. (2013). Nature and extent of the deep biosphere. Rev. Mineral Geochem. 75, 547-574. doi: 10.2138/rmg.2013.75.17

Demazeau, G., and Rivalain, N. (2011). High hydrostatic pressure and biology: a brief history. Appl. Microbiol. Biotechnol. 89, 1305-1314. doi: 10.1007/s00253010-3070-9

Edwards, K. J., Becker, K., and Colwell, F. (2012). The deep, dark energy biosphere: intraterrestrial life on Earth. Ann. Rev. Earth Planet. Sci. 40, 551-568. doi: 10.1146/annurev-earth-042711-105500

Feder, M. E., and Hofmann, G. E. (1999). Heat-shock proteins molecular chaperones and the stress response evolutionary and ecological physiology. Ann. Rev. Physiol. 61, 243-282. doi: 10.1146/annurev.physiol.61.1.243

Griffin, P. L., Kish, A., Steele, A., and Hemley, R. J. (2011). Differential high pressure survival in stationary-phase Escherichia coli MG1655. High Pressure Res. 31, 325-333. doi: 10.1080/08957959.2010.550891

Guo, H., Wang, Y., Liu, X., Yan, T., Wu, L., Alm, E., et al. (2004). Global transcriptome analysis of the heat shock response of Shewanella oneidensis. J. Bacteriol. 186, 7796-7803. doi: $10.1128 / \mathrm{JB} .186 .22 .7796-7803.2004$

Guo, H., Yang, Z. K., Wu, L., Thompson, D. K., and Zhou, J. (2006). Global transcriptome analysis of the cold shock response of Shewanella oneidensis MR1 and mutational analysis of its classical cold shock proteins. J. Bacteriol. 188, 4560-4569. doi: 10.1128/JB.01908-05

Hartl, F. U. (1996). Molecular chaperones in cellular protein folding. Nature 381, 571-580. doi: 10.1038/381571a0

Hartl, F. U., Bracher, A., and Hayer-Hartl, M. (2011). Molecular chaperones in protein folding and proteostasis. Nature 475, 324-332. doi: 10.1038/ nature 10317

Hauben, K., Bartlett, D. H., Soontjens, C. C., Cornelis, K., Wuytack, E. Y., and Michiels, C. W. (1997). Escherichia coli mutants resistant to inactivation by high hydrostatic pressure. Appl. Environ. Microbiol. 63, 945-950.

Hill, G. L., Bailey, E., Stennett, M. C., Hyatt, N. C., Maddrell, E. M., McMillan, P. F., et al. (2011). High pressure and temperature ion exhange of aluminosilicate and gallosilicate natrolite. J. Am. Chem. Soc. 133, 13883-13885. doi: $10.1021 / \mathrm{ja} 205680 \mathrm{c}$ 
Hite, B. H., Giddings, N. J., and Weakley, C. E. Jr. (1914). The Effect of Pressure on Certain Micro-Organisms Encountered in the Preservation of Fruits and Vegetables. Morgantown, WV: West Virginia University, Agricultural Experiment Station, $146,1-67$.

Iwahashi, H., Fujii, S., Obuchi, K., Kaul, S. C., Sato, A., and Komatsi, Y. (1993). Hydrostatic pressure is like high temperature and oxidative stress in the damage it causes to yeast. FEMS Microbiol. Lett. 108, 53-58. doi: 10.1111/j.1574-6968.1993.tb06073.x

Karatzas, K. A. G., Valdramidis, V. P., and Wells-Bennik, M. H. J. (2005). Contingency locus in ctsR of Listeria monocytogenes Scott A: a strategy for occurrence of abundant piezotolerant isolates within clonal populations. Appl. Environ. Microbiol. 71, 390-396. doi: 10.1128/AEM.71.12.8390-8396.2005

Kato, C., and Nogi, Y. (2001). Correlation between phylogenetic structure and function: examples from deep-sea Shewanella. FEMS. Microbiol. Ecol. 35, 223 230. doi: 10.1111/j.1574-6941.2001.tb00807.x

Kawamoto, J., Sato, T., Nakasone, K., Kato, C., Mihara, H., Esaki, N., et al. (2011) Favourable effects of eicosapentaenoic acid on the late step of the cell division in a piezophilic bacterium, Shewanella violacea DSS12, at high-hydrostatic pressures. Environ. Microbiol. 13, 2293-2298. doi: 10.1111/j.1462-2920.2011.02487.x

Kish, A., Griffin, P. L., Rogers, K. L., Fogel, M. L., Hemley, R. J., and Steel, A. (2012). High-pressure tolerance in Halobacterium salinarum NRC-1 and other non-piezophilic prokaryotes. Extremophiles 16, 355-361. doi: 10.1007/s00792011-0418-8

Lauro, F. M., Chastain, R. A., Ferriera, S., Johnson, J., Yayanos, A. A., and Bartlett, D. H. (2013). Draft genome sequence of the deep-sea bacterium Shewanella benthica strain KT99. Genome A 1, e00210-13. doi: 10.1128/genomeA.00210-13

Meersman, F., Daniel, I., Bartlett, D., Winter, R., Hazael, R., and McMillan, P. F. (2013). High pressure biophysics and biochemistry. Rev. Mineral. Geochem. 75, 607-648. doi: 10.2138/rmg.2013.75.19

Meersman, F., and McMillan, P. F. (2014). High hydrostatic pressure: a probing tool and a necessary parameter in biophysical chemistry. Chem. Commun. 50, 766-775. doi: $10.1039 / \mathrm{c} 3 \mathrm{cc} 45844 \mathrm{j}$

Oger, P., and Jebbar, M. (2010). The many ways of coping with pressure. Res. Microbiol. 161, 799-809. doi: 10.1016/j.resmic.2010.09.017

Picard, A., and Daniel, I. (2014). Pressure as an environmental parameter for microbial life-A review. Biophys. Chem. 183, 30-41. doi: 10.1016/j.bpc.2013.06.019

Picard, A., Testemale, D., Hazemann, J. L., and Daniel, I. (2012). The influence of high hydrostatic pressure on bacterial dissimilatory iron reduction. Geochim. Cosmochim. Acta 88, 120-129. doi: 10.1016/j.gca.2012.04.030

Schuster, B., and Sleytr, U. B. (2002). The effect of hydrostatic pressure on Slayer-supported lipid membranes. Biochim. Biophys. Acta 1563, 29-34. doi: 10.1016/S0005-2736(02)00370-X

Sharma, A., Scott, J. H., Cody, G. D., Fogel, M. L., Hazen, R. M., Hemley, R. J., et al. (2002). Microbial activity at gigapascal pressures. Science 295, 1514-1516. doi: $10.1126 /$ science. 1068018

Subramaniam, A. B., Guidotti, G., Manoharan, V. N., and Stone, H. A. (2013). Glycans pattern the phase behaviour of lipid membranes. Nat. Mater. 12, 128-133. doi: $10.1038 /$ nmat3492
Vanlint, D., Mitchell, R., Bailey, E., Meersman, F., McMillan, P. F., Michiels, C. W., et al. (2011). Rapid acquisition of gigapascal-high-pressure resistance by Escherichia coli. Mbio 2, 1-3. doi: 10.1128/mBio.00130-10

Vanlint, D., Pype, B. J. Y., Rutten, N., Vanoirbeek, K. G. A., Michiels, C. W., and Aertsen, A. (2013a). Loss of cAMP/CRP regulation confers extreme high hydrostatic pressure resistance in Escherichia coli O157:H7. Int. J. Food. Microbiol. 166, 65-71. doi: 10.1016/j.ijfoodmicro.2013.06.020

Vanlint, D., Rutten, N., Govers, S. K., Michiels, C. W., and Aertsen, A. (2013b). Exposure to high hydrostatic pressure rapidly selects for increased RpoS activity and general stress-resistance in Escherichia coli O157:H7. Int. J. Food. Microbiol. 163, 28-33. doi: 10.1016/j.ijfoodmicro.2013.02.001

Van Opstal, I., Vanmuysen, S. C. M., Wuytack, E. Y., Masschalck, B., and Michiels, C. W. (2005). Inactivation of Escherichia coli by high hydrostatic pressure at different temperatures in buffer and carrot juice. Int. J. Food. Microbiol. 98, 179-191. doi: 10.1016/j.ijfoodmicro.2004.05.022

Venkateswaran, K., Moser, D. P., Dollhopf, M. E., Lies, D. P., Saffarini, D. A., MacGregor, B. J., et al. (1999). Polyphasic taxonomy of the genus Shewanella and description of Shewanella oneidensis sp. nov. Int. J. Syst. Bacteriol. 49, 705-724. doi: 10.1099/00207713-49-2-705

Wuytack, E. Y., Diels, A. M. J., and Michiels, C. W. (2002). Bacterial inactivation by high-pressure homogenisation and high hydrostatic pressure. Int. J. Food Microbiol. 77, 205-212. doi: 10.1016/S0168-1605(02)00054-5

Yayanos, A. A. (2002). Are cells viable at gigapascal pressures? Science 297, 295. doi: $10.1126 /$ science.297.5580.295a

Yin, J., and Gao, H. (2011). Stress responses of Shewanella. Int. J. Microbiol. 863623, 1-8. doi: 10.1155/2011/863623

ZoBell, C. E., and Johnson, F. H. (1949). The influence of hydrostatic pressure on the growth and viability of terrestrial and marine bacteria. J. Bacteriol. 57, 179-189.

Conflict of Interest Statement: The authors declare that the research was conducted in the absence of any commercial or financial relationships that could be construed as a potential conflict of interest.

Received: 23 July 2014; accepted: 28 October 2014; published online: 17 November 2014.

Citation: Hazael R, Foglia F, Kardzhaliyska L, Daniel I, Meersman F and McMillan $P$ (2014) Laboratory investigation of high pressure survival in Shewanella oneidensis MR-1 into the gigapascal pressure range. Front. Microbiol. 5:612. doi: 10.3389/fmicb.2014.00612

This article was submitted to Extreme Microbiology, a section of the journal Frontiers in Microbiology.

Copyright (c) 2014 Hazael, Foglia, Kardzhaliyska, Daniel, Meersman and McMillan. This is an open-access article distributed under the terms of the Creative Commons Attribution License (CC BY). The use, distribution or reproduction in other forums is permitted, provided the original author(s) or licensor are credited and that the original publication in this journal is cited, in accordance with accepted academic practice. No use, distribution or reproduction is permitted which does not comply with these terms. 